\title{
Individual perception about the gratification of social and traditional media in Pakistan
}

\author{
Wajid Zulqarnain ${ }^{1 *}$, Naveed Ullah Hashmi ${ }^{2}$, Amna Zulqarnain ${ }^{3}$ \\ 1, 2,3 Department, Media Sciences, SZABIST University, Islamabad, Pakistan
}

\section{Keywords \\ Social media \\ Traditional media \\ Individual perception \\ Gratification}

Received: 4 October 2019

Accepted: 7 November 2019

Published: 23 December 2019

\begin{abstract}
The current study aimed at exploring the difference between traditional and social media news and analyzed their role in gratification of informational needs on the basis of gender and usage. Five categories of local, national, international, disaster and entertainment are selected for the survey, consisting of 1383 male and female university students from the capital of each province of Pakistan. The results are statistically analyzed by using SPSS. The findings suggest that social media remain active to satiate informational needs, and the dependency of traditional media on social media posit that soon traditional media would be displaced. The obtained gratification and individual perception of participants are found significant for social media than traditional media. The moderation effect of gender and usage is also momentous. Male dominance is not only prevalent in social structure but also evident in media consumption patterns. The social and gender disparities are reflective in this current study in informational need gratification through media.
\end{abstract}

(C) 2019 The Author(s). Published by TAF Publishing

\section{INTRODUCTION}

The social media brought drastic changes in human communication and social networking sites such as Facebook, Twitter, YouTube, Google+ etc brought people at the same platform and blessed with numerous opportunities for communication and information sharing. The previous findings showed that $90 \%$ internet users can name at least one social networking site and Facebook has 500 million registered users and 2 billion people each day hit YouTube (Hanna, Rohm, \& Crittenden, 2011). The rapid penetration of social media in common citizen excited media scholars to conceptualize the understanding and effects of social media. The hard area for scholars was to understand specifically how these social media networks affect the world today and particularly explore effect of social media in daily routine.

In Pakistan social networking sites like Facebook, Twitter, Instagram, YouTube, and Google+ are well-liked and widely used means of interpersonal and public communication. Social networking sites are modern interactive communi- cation channels through which people connect to one another, share ideas, experiences, pictures, messages and information of interest. Further Social networking sites became channel of information and started gratifying human needs. By keeping in view, the gradual development in social networking sites compelled traditional media to incorporate this new media into media practices to gain feedback from the users and further accelerate purpose of the media which revolves around gratifying needs i.e., information and keep the people up-dated with latest happening (Appleyard, 1999) termed this development of new media a "fabulous monster" as it is dominating traditional news media and traditional media is migrating to online media.

It not only facilitates to reach infinite audience without much cost but also help to construct better news story according to target audience and their perception as it is two-way communication, in-depth coverage, multimedia presentation and search-ability (Nguyen, Ferrier, Western, \& McKay, 2005). Further, 27/7 accessibility, archive,

\footnotetext{
*corresponding author: Wajid Zulqarnain

†email: wajidgeo@yahoo.com
} 
and availability of the news on internet made new media a threat for traditional news media. The undaunted progress of new media has become an ideal source of news to the public. The extended and proliferation of media choices due to traditional and social media, people are constantly selecting media which are actually imperfect substitute (Dimmick, Chen, \& Li, 2004; Uggur \& Barutcu, 2018). Therefore, the first question can be what is the impact of Social Media and Traditional Media Gratification on Individual perception? Consequently, the current study was conducted to measure the level of individual perception of gratification about social and traditional media, particularly in information domain. As in Pakistan, for last few years, it is observed that different news got prominent place in traditional and mainstream media due to social media. The usage and reliance of social media increased and similarly the new researches explored how social media is playing its role in disseminating news. As this gives people to gain greater access to information worldwide and they can contribute in current issues. Therefore, the second and third questions are Does Social Media Usage moderate the relationship between Social Media Gratification and Individual perceptions? Does Traditional Media Usage moderate the relationship between Traditional Media Gratification and Individual perceptions?

In past researches it has been observed that gender remained an important factor in the usage of social or traditional media. Significant changes and trends have been found that male and female have different gratification level and they deal social and traditional media differently. Therefore considering the over-increasing role of social media in young generation, the following research questions need to be addressed. Do gender moderates the relationship between Social Media Gratification and Individual perceptions? Do gender moderates the relationship between Traditional Media Gratification and Individual perceptions? The present study examined obtained gratification from reading news on social and traditional media and found role of usage and gender as moderator in gratification and individual perception. Social media included Facebook, YouTube, Google+, Twitter and traditional media included Television, Radio, Newspapers and Magazines. The both type of news i.e., hard and soft news were selected and further five news categories were given to respondent which included local news, national news, international news, disaster news and entertainment news. The university students both male and female were selected as sample of the study.

\section{LITERATURE REVIEW}

The content comparison of local and national news from six newspapers has been analyzed and showed that online news has stronger local perspective than print news (Nuchso, Tuntivivat, \& Klayklueng, 2016; Singer, 2001). From the viewpoint of the public responsibility, usage of new media for the purpose of projection of news media is to convey news and to keep updated. Civic responsibility to keep updated for news is like the relationship of usage of cable news and national news on online platforms and news through traditional modes, and then civic responsibility is also related with the education and has great impact on the usage of new media for the purpose of deliverance of news. Some studies also investigated consumer insight for the internet news (Poindexter \& McCombs, 2001). According to a research four standards have been used by audience of the news, which are representativeness, credibility, liking and quality (Peng, 2019; Sundar, 1999). Some previous studies disclosed that people have different level of gratification about seeking the information or news from particular source; social or traditional. Therefore it is hypothesized that:

H1: Social Media Gratification has a positive impact on Individual Perception.

H2: Traditional Media Gratification has a positive impact on Individual Perception.

It has also been observed that news stories with quotes are regarded highly credible and considered more quality based than same stories having no quotes, while quotes are more associated with other two standards of internet news that are liking and representativeness (Sundar, 1998). To analyze the credibility of internet world, the opinion of people for different types of medias have been compared, which showed that online information was regarded as credible as traditional media like television, radio, and magazines, however not as credible as information from newspaper (Flanagin \& Metzger, 2000). The impact of multimedia on people in receiving information from websites of internet news has also been examined, which showed that the usage of multimedia like audio, video and pictures on web sites enhanced the tendency of improved memory for the advertisements amongst people, however it is inclined to deter memory for the content of the story. The role of online news has been compared with other types of media in several studies and a lot of research literatures. The portrayal and developments of online news in numerous situations with diverse characteristics of online news has been studied in nine researches (Sundar, 2000). According to a study, people who 
use internet for gaining news are likely to read newspapers as well, however did not use television for news purposes. It has also been studied that in spite of the fact that the access of internet is very easy and there are enhanced computer skills in this networked community, the chances of reduced use of traditional media for news because of the usage of online news are very few. These patterns were surveyed in a large public university, where usage of internet is very common and part of daily life. It was also observed that in this community internet was mostly used for the entertainment purposes (Tewksbury \& Althaus, 2000). Another study reinforced the same point of view, in which a 5-year-long national survey of media usage showed an enormous achievement of online news usage and depletion of newspaper television news usage. Although, it is believed that Internet is not liable for the reduced usage of traditional media when it comes to news. Consequently, earlier researches showed that the use of Internet news from the user's perceptions have certainly produced numerous effects. Usage of internet news as compared with traditional types of news media has been examined by many researches. Althaus and Tewksbury (2000) Then in another research, a considerable growth of use of online news with a decrease in the usage of traditional news platforms, according to a survey report about one out of three citizen from US uses internet for news, which shows considerable increase in the percentage of users that was 20\% in year 1998 (Dimmick et al., 2004). During this time, report also depicted a fall in the usage of network news from $38 \%$ to $30 \%$, then another decrease of viewership from $64 \%$ to $56 \%$ in local network news has been observed (Poindexter \& McCombs, 2001). Both studies shows displacement shift, that Internet news has replaced traditional modes of news. But, prior researches have not showed direct differences of usage and competitive effect between the online news and traditional news. Therefore to verify the findings of these studies, following hypothesis are made:

H3: Social Media Usage moderates the relationship between Social Media Gratification and Individual Perception. H4: Traditional Media Usage moderates the relationship between Traditional Media Gratification and Individual Perception.

Some questions are still unanswerable like: What is the motivation for people behind using online news or traditional news? What are the difference between the services provided by online news and traditional news and if these are in accordance with the needs of their audience? Research aims at the knowing the internet news media versus tradi- tional news media. Gratifications may indicate the reduced usage of traditional means for news. Internet news and traditional news consumption has been analyzed on the basis of its everyday use. The research also depicted theoretical way that includes usage of mediums, niche and gratifications theory Progress and advancements in technology has been mostly intrigued by the changes in the human society which in return has evolved the conduct of media (Althaus \& Tewksbury, 2000). As a result, "New media" also known as digital media or Information Communications Technologies (ICTs) emerged in 21st century .It was a combination of innovative and advancing technologies and has greatly influenced the media industry. Despite the fact that media was undergoing changes for more than 40 years , new media has revolutionized it dramatically. New media is a major part of media sciences and it is comprised of new ICTs , computer dependent creative activities, multimedia, web and cellular phones. "New Media " has been tried to be replaced with "online or digital media" in few communication studies. Until the beginning of 21 st century, conventional platforms like television, radio and newspapers ruled the media industry and had been a major source for mass communications. Mostly because of the general perception till 1999 that internet was comparable to telephone and it could not contribute as a part of mass communication even if each home is equipped with a computer linked to a modem. This perception changed after 2000 and it was obvious that era of new information have arrived and would act as a competition for traditional mediums and would eventually challenge and evolve the existing sources of mass communication. Recent studies in media revealed that components of new media like internet and cellular phones have a strong hold on society especially in younger generation as a news consumption outlet. The theoretical understanding and the previous literature guide us to develop our hypotheses:

H5: Gender moderates the relationship between Social Media Gratification and Individual Perception.

H6: Gender moderates the relationship between Traditional Media Gratification and Individual Perception.

It was supported by the fact that in 2003,70 percent of reading news related to business and world affairs in 12 core European countries was at second spot as a part of online activities. It seems that the conventional mass media has made peace with the existence and emergence of new media and is trying to move in the direction of new media calling it media convergence. The advancements in new media is posing serious threats for the survival of old mass communication mediums like newspapers and televisions. It 
is feared that new media devices like smartphones which are extensively used in everyday life for browsing, socially connecting with other people and performing functions like controlling electronic devices such as cameras and Digital Video Record (DVR) will take over old mediums. The threat is real because of the statistical facts from 2010 which stated that there are almost 500 million social media profiles, depicting the increased usage of new media and discouraging any doubts related to new media as a major news outlet. The question now is how much old news media platforms are being affected by new media and online news. There is a difference of opinion regarding that where one group clearly states that new media is replacing traditional platforms as a medium of news outlet whereas the other faction thinks that the new media is acting as a supporting element for the old media because of which old media is still exiting and striving. It is an ongoing debate since 2011 and probably will continue because of lack of any differentiating pattern between the new and traditional news medium as a news consumption source. This resulted in recommending a deviation from old and traditional approaches where media and social interactions are treated separately. To develop a clear pattern between the two news mediums, it is required to study news consumptions in both of them keeping uses and gratification approach, giving a preference of users inclinations over media attributes.

\section{METHODOLOGY}

Among the uses and gratifications frameworks available in the literature, this study used the Poindexter and McCombs (2001) scale was selected because it was the first to look at both uses and gratifications simultaneously and because it looked at television viewing which is somewhat similar in nature to social media. For the current study, a survey method was designed and university students were asked regarding their media use and perceptions of gratification. The questionnaire was the tool and divided into three sections including media use, media gratification, and demographic sections. All the questions were close-ended and mostly questions were based on 5-point Likert scale. At first stage, the Higher Education Commission (HEC) recognized Pakistan universities have been nominated from both sectors public and private sector. At second stage, universities situated in all provinces' capital cities including Federal capital were selected. Sample consists of 25 private and 25 public sector universities. At third stage, to accumulate respondents for this investigation, an example of Male and female understudy's age 17 years to 36 and above years utilizing social and customary media was created. People were reached by and by and survey was appropriated among the understudies during their group, under the supervision of specialist.

\section{RESULTS}

TABLE 1. Respondents' gender frequency

\begin{tabular}{ll}
\multicolumn{2}{c}{ results } \\
\hline \hline $\boldsymbol{N}$ & $\mathbf{1 3 8 3}$ \\
\hline Gender & Frequency \\
& 833 \\
Male & 550 \\
Female & \\
Age & 207 \\
$15-20$ & 462 \\
$21-25$ & 468 \\
$26-30$ & 170 \\
$31-35$ & 76 \\
36 and above & \\
Education Completed (in years) & \\
12 & 810 \\
14 & 273 \\
16 & 195 \\
18 and above & 105 \\
Universities & \\
Islamabad & 330 \\
Lahore & 192 \\
Karachi & 356 \\
Peshawar & 165 \\
Quetta & 150 \\
Gilgit Baltistan & 70 \\
Muzaffarabad & 120 \\
\hline \hline
\end{tabular}

Table 1 shows respondents' gender frequency results. The male was coded for 1 while the female was coded as 2 in the instrument. Out of 1383 respondents, 833 were males while 550 were females. This shows that in the data the male respondents were greater than the female ones. Table shows the age of the respondents. In the age categories the 15-20 years was coded as 1, 21-25 years was coded as 2 , 26-30 years was coded as 3, 31-45 years was coded as 4 and 36 or more years was coded as 5 . The consequences of the investigation show that there were 207 respondents that had a place with 15-20 years old. 462 participants were of 21-25 years of age, 468 respondents were from 26-30 years of age. 31-35 years of age were 170 respondents and above 36 years of age were only 76 . Table 3 shows education level of participants. Total four categories of education question were made going from 12 years of training of 18 or above long periods of instruction. The 12 years of instruction was coded as 1, 14 years as 2, 16 years as 3 and 18 or above was coded as 4 . It is demonstrated that the majority of the respondents were having 12 years of training for example 810 respondents, 273 have 14 years of education, 195 have 
16 years of education and 105 respondents indicated their education above 18 years. The results show that mostly respondents havea 12 years of education. Table shows the results of the different areas from which respondents belong to.

TABLE 2. Media usage trend of the respondents

\begin{tabular}{ll}
\hline \hline News Type & Frequency \\
\hline I use Media (Social \& Traditional) for & \\
Local News & 435 \\
National News & 220 \\
International News & 29 \\
Disaster \& relief Activities News & 321 \\
Entertainment News & 378 \\
Which media do you use & \\
Social & 524 \\
Traditional & 483 \\
Social and Traditional & 376 \\
I use social media for & \\
Hard News & 192 \\
Soft News & 442 \\
Both Soft and Hard News & 746 \\
\hline \hline
\end{tabular}

Table 2 shows the media usage trend of the respondents. Out of the sample of 1383, three types of media users were identified i.e., "only social media users" coded as 1 , "only traditional media users" coded as 2 and "social and traditional media users"coded as 3 . The analysis shows that 524 respondents were using social media only, while 483 were traditional media users. 376 respondents were user of social and traditional media both. But the analysis of the results proves that mostly respondents were social media users. Table shows the consequences of the utilization of internet based life use for various sort of news. The hard news was coded as 1 , the delicate news was coded as 2 and both delicate and hard news was coded as 3 . It is seen that respondent utilize online networking for delicate news were 442, for hard news 192 and for both delicate and hard news are 746 . The outcomes demonstrate that a large portion of the individuals utilize internet based life for hard news.

TABLE 3. Descriptive Statistics

\begin{tabular}{lllll}
\hline \hline & Mean & Std. Deviation & Skewness & Kurtosis \\
\hline SMG & 3.9853 & 0.3898 & -0.765 & 0.532 \\
TMG & 3.8873 & 0.4764 & -0.948 & 1.698 \\
IP & 4.0814 & 0.5003 & -0.739 & 0.542 \\
\hline \hline
\end{tabular}

Table 3 shows the results of descriptive statistics of the variables. For the primary data analysis purpose the mean, standard deviation, kurtosis and skewness were calculated. The values of descriptive for different variables were well within the range i.e., for SMG $(M=3.98, S D=.3898$, Skewness $=-0.765$, Kurtosis $=0.532)$, for TMG $(M=3.88, S D=$ .4764 , Skewness $=-0.948$, Kurtosis $=1.698)$ and for IP $(M=$ $4.08, S D=.5003$, Skewness $=-0.739$, Kurtosis $=0.542$ ).

TABLE 4. Correlations

\begin{tabular}{llll}
\hline \hline & SMG & TMG & IP \\
\hline SMG & 1 & & \\
TMG & $.236^{* *}$ & 1 & \\
IP & $.736^{* *}$ & $.210^{* *}$ & 1 \\
\hline \hline
\end{tabular}

Table 4 shows the results of the correlation between different variables of the study. SMG has weak but positive correlation $(r=.736, p=0.000)$ with IP. This indicates that with the increase of SMG the IP will also increase. But TMG has positive and strong correlation $(r=.210, p=0.000)$ with IP. This indicates that with the increase of TMG the IP will also increase.

TABLE 5. Direct test

\begin{tabular}{|c|c|c|c|c|c|}
\hline Hypothesis & $\overline{R^{2}}$ & 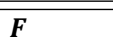 & 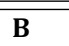 & 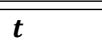 & $\overline{p p}$ \\
\hline H1: Social Media Gratification has positive impact on Individual Perception & .541 & 820.524 & .933 & 38.826 & .0000 \\
\hline H2: Traditional Media Gratification has a positive impact on Individual Perception & & & .041 & 2.065 & .0000 \\
\hline
\end{tabular}

Table 5 shows the results of the direct hypothesis testing. For $\mathrm{H} 1$ it is seen that $5.4 \%$ of the variation $\left(R^{2}=0.541, F\right.$ $=820.524$ ) in IP is being caused by SMG and model is fit for regression. The value of coefficient shows ( $\beta=0.933$ ) that with one unit change in SMG .933 units will positively change in IP. The results of hypothesis testing are significant $(t=38.826, p=0.00)$ that hypothesis is fully supported that SMG has a positive impact on IP.
For $\mathrm{H} 2$ it is seen that $0.4 \%$ of the variation $\left(R^{2}=0.541, F\right.$ $=820.524$ ) in IP is being caused by TMG and model is fit for regression. The value of coefficient shows $(\beta=0.041)$ that with one unit change in TMG .041 units will positively change in IP. The results of hypothesis testing are significant $(t=2.065, p=0.00)$ that hypothesis is fully supported that TMG has a positive impact on IP. 
TABLE 6. Conditional effect of SMG and TMG on IP at values of the moderator

\begin{tabular}{|c|c|c|c|c|c|c|}
\hline SMU & Effect & se & 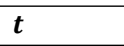 & $p$ & LLCI & ULCI \\
\hline \multicolumn{7}{|c|}{ H3: Social Media Usage moderates the relationship between Social } \\
\hline \multicolumn{7}{|c|}{ Media Gratification and Individual Perception } \\
\hline-0.6727 & .9349 & .0390 & 23.9678 & 0.000 & .8584 & 1.0114 \\
\hline 0.0000 & .9448 & .0252 & 37.4733 & 0.000 & .8953 & .9942 \\
\hline 0.4324 & .9511 & .0298 & 31.8668 & 0.000 & .8926 & 1.0097 \\
\hline \multicolumn{7}{|c|}{ H4: Traditional Media Usage moderates the relationship between } \\
\hline \multicolumn{7}{|c|}{ Traditional Media Gratification and Individual Perception. } \\
\hline-0.7346 & .2133 & .0339 & 6.2861 & 0.000 & .1467 & .2799 \\
\hline 0.0000 & .2197 & .0245 & 8.9748 & 0.000 & .1716 & .2677 \\
\hline 0.8359 & .2269 & .0343 & 6.6172 & 0.000 & .1596 & .2941 \\
\hline
\end{tabular}

Table 6 shows the results of $\mathrm{H} 3$ and $\mathrm{H} 4$, For $\mathrm{H} 5$ the results show that social media usage moderates the relationship between Social Media Gratification and Individual Perception. According to the result i.e., $(.9349, .9448 \& .9511)$ moderation analysis results support the hypothesis that more usage of social media strengthens the relationship between Social Media Credibility and Individual Perception.
The results $\mathrm{H} 4$ show that Traditional media usage moderates the relationship between Traditional Media Gratification and Individual Perception. According to the result i.e., $(.2133, .2197 \& .2269)$ moderation analysis results support the hypothesis that more usage of social media strengthens the relationship between Traditional Media Gratification and Individual Perception.

TABLE 7. Conditional effect of SMG and TMG on IP at values of the moderator

\begin{tabular}{|c|c|c|c|c|c|c|}
\hline Gender & Effect & se & $t$ & $p$ & LLCI & ULCI \\
\hline \multicolumn{7}{|c|}{$\begin{array}{l}\text { H5: Gender moderates the relationship between So- } \\
\text { cial Media Gratification and Individual Perception }\end{array}$} \\
\hline 1.0000 & 0.9595 & 0.0327 & 29.3339 & 0.000 & 0.8953 & 1.0236 \\
\hline 2.0000 & 0.9227 & 0.0394 & 23.4424 & 0.000 & 0.8454 & 0.9999 \\
\hline \multicolumn{7}{|c|}{$\begin{array}{l}\text { H6: Gender moderates the relationship between Tra- } \\
\text { ditional Media Gratification and Individual Perception }\end{array}$} \\
\hline 1.0000 & 0.2390 & 0.0310 & 7.7028 & 0.000 & 0.1781 & 0.2998 \\
\hline 2.0000 & 0.1906 & 0.0395 & 4.8212 & 0.000 & 0.1130 & 0.2681 \\
\hline
\end{tabular}

Table 7 shows the results of the moderating effects of gender between Social Media Gratification and IP. It is seen that male $\beta=0.9595, t=29.3339$, $[.8953,1.0236]$ and female $\beta=$ $0.9227, t=23.4424,[.8454, .9999]$ media users show positive moderation between the relationship of Social Meida Gratification and IP. The results also depict that in comparison to female media users the male media users have more IP. For $\mathrm{H} 6$ the results of the moderating effects of gender between Traditional Media Gratification and IP. It is seen that male $\beta=0.2390, t=7.7028$, [.1781, 0.2998] and female $\beta=$ $0.1906, t=4.8212,[.1130, .2681]$ media users show positive moderation between the relationship of Traditional Media Gratification and IP. The results also depict that in comparison to female media users the male media users have more IP.

\section{DISCUSSION}

This study investigated the Individual perception about the gratification of Social and Traditional Media in Pakistan and survey was conducted in selected 7 major cities of Pakistan which were selected randomly. The study was focused on informational need i-e news and found which media either social or traditional gratify informational need. The findings of the current study are consistent with the previous researches (Hall, 2013).

The current study ( $n=1383)$ was conducted in 7 big cities of Pakistan and university students were selected to get their responses about the traditional and social media gratification. In this research 833 respondents were male students and 550 were female students. Other demographics included age and education, selected age of participants was 17 years to 36 years and above whereas level of education was from 12 years of education to Ph.D. majority of the respondents were from Karachi (356) and Islamabad (330), 468 participants were of age (26-30) and 462 were of (21-25) respectively. The results indicated that 810 participants had completed their 12 years of education and 273 were of 14 years graduate. The education and knowledge 
of the audience is integral in news consumption. In previous studies it was found that people with higher education levels have more knowledge about the news because of accessibility and more inclination to news consumption (Schrøder, 2015). This results in "knowledge gap" between higher and lower educated people (Tichenor, Donohue, \& Olien, 1970). Knowledge gap theory has influenced more recent journalism research, including knowledge acquisition and news habits among college students and differences between online and print newspaper readers' information absorption (Althaus \& Tewksbury, 2000).

These findings reiterated the fact that media exposure and consumption is higher in male, in metropolitan cities like Karachi and Islamabad and Lahore, the age group from 21 to 30 years is more vulnerable to media. As media content is dominated by male, similarly the media usage is higher in male; it highlights the patriarchal social structure which restricts women not only in media practices but in consumption as well. Further the accessibility of the resources in big cities, extends the opportunities to its dwellers therefore, media usage was found more in developed cities. The gratification media study encompasses factors which lead to gratification such as socialization, information, communication, escapism and emotional help etc, therefore the age group from 21 years to 30 years used media for numerous purposes. The current era of technology had revolutionized socialization and communication patterns, particularly the adoption of social media in every field brought changes, therefore mostly respondents indicated that they used social media 524 and traditional media was used by 483 participants. On the other side, 376 respondents were using both traditional and social media. It reinforced that now people are media specific, either they use social media or traditional media but the social media usage is higher due to its accessibility, speed and user control. As the growth of media converted passive audience to active audience therefore reliance and usage is more of social media. In recent scenario both media play active role in news domain, traditional media keep the people updated by $24 / 7$ breaking news phenomena and social media constantly tweets the news. The usage of social media for Hard news is higher than soft news. 582 respondents used social media for hard news i-e current news. Further news categories include local news, national news, international news, disaster news and entertainment news. The results showed that mostly participants (435) used media for local news. Local news is about their locality and area in which they are keener to know. The elements of news such as proximity are relevant with local news. People are more interested in lo- cal news than other news. Another finding of the current study indicated that 378 participants used media for entertainment news, it correlates with soft news. Entertainment news is about sports, showbiz, fashion, music in short about entertainment industry. Users are curious to know what is happening in entertainment industry, particularly in showbiz word and wanted to know about celebrities activities. Due to growing prominence of social media as a news channel, it was researched to see how an audience perceives news through online media. it was found that many people log onto social media sites for breaking news coverage, and they acquire knowledge in the same way as they have from reading a newspaper or watching TV News, such crisis news; (Hall, 2013) building credibility between politicians and their audience during political campaigns; (Johnson, 2012) and reporting national and international event (Chew \& Eysenbach, 2010).

The findings described that social media gratification and individual perception is positively correlated, increase in social media gratification $(r=.736)$ would results in increase in individual perception. The provision of different stories from variety of sources but on same platform i-e social media for heterogeneous audience, according to social value; result in more reliance on social media (Grimmer, Messing, \& Westwood, 2012).

The H1 was supported by the results that Social Media Gratification has a positive impact on Individual Perception ( $t$ = 38.826) and similarly the findings further supported $\mathrm{H} 3$ which stated Social Media Usage moderates the relationship between Social Media Gratification and Individual Perception.

The role of gender is integral in media usage and the results supported $\mathrm{H} 5$ which was about the moderating role of gender in gratification and individual perception. The findings provided the fact that social media was used more by male to gratify informational needs. This correlates with higher usage by male respondents.

\section{CONCLUSION}

The findings of the current study suggest that the strategy of attracting users via social media is succeeding. Social media was found the fastest growing source of major news websites. Furthermore, this trend seems likely to continue and assumed that social media will replace traditional media as mainstream media is relying on social media; gradually traditional media's role in conveying news is declining and the internet now constitutes the main source of news for a majority of people. Now it is evident that the relationship between social media and news consumption is a fundamental 
part of media environment.

Now with the emergence of internet and social media, people have choice, if the local news is ignored on traditional media, audience disseminate it through social media and it finally become headline on mainstream media. The audience is no more passive recipient of information; they can share their topics of interests and can incite people with similar issues or interest through social media.

In Pakistani context, the gender role in gratifying informa- tional need through social media is also evidence and found male-dominances effect here in the study in social media consumption and need gratification as well.

\section{LIMITATIONS AND RECOMMENDATIONS}

A cross-sectional research design is the limitation of the study. This study must be replicated with a more stringent research design. This will lend confidence to the findings and provide fine-grained results.

\section{REFERENCES}

Althaus, S. L., \& Tewksbury, D. (2000). Patterns of internet and traditional news media use in a networked community. Political Communication, 17(1), 21-45. doi:https://doi.org/10.1080/105846000198495

Appleyard, B. (1999). Under the net. New Statesman, 128(4457), 56-70.

Chew, C., \& Eysenbach, G. (2010). Pandemics in the age of twitter: Content analysis of tweets during the 2009 H1N1 outbreak. PloS One, 5(11), 56-70. doi:https://doi.org/10.1371/journal.pone.0014118

Dimmick, J., Chen, Y., \& Li, Z. (2004). Competition between the internet and traditional news media: The gratificationopportunities niche dimension. The Journal of Media Economics, 17(1), 19-33. doi:https://doi.org/10.1207/ s15327736me1701_2

Flanagin, A. J., \& Metzger, M. J. (2000). Perceptions of internet information credibility. Journalism \& Mass Communication Quarterly, 77(3), 515-540. doi:https://doi.org/10.1177/107769900007700304

Grimmer, J., Messing, S., \& Westwood, S. J. (2012). How words and money cultivate a personal vote: The effect of legislator credit claiming on constituent credit allocation. American Political Science Review, 106(4), 703-719. doi:https:// doi.org/10.1017/s0003055412000457

Hall, A. E. (2013). Tweeting the headlines: The impact of social media endorsement on young adult news readers (Unpublished master's thesis). University of Missouri, Columbia, Missouri.

Hanna, R., Rohm, A., \& Crittenden, V. L. (2011). We're all connected: The power of the social media ecosystem. Business Horizons, 54(3), 265-273. doi:https://doi.org/10.1016/j.bushor.2011.01.007

Johnson, J. (2012). Twitter bites and romney: Examining the rhetorical situation of the 2012 presidential election in 140 characters. Journal of Contemporary Rhetoric, 2(6), 45-60.

Nguyen, A., Ferrier, E., Western, M., \& McKay, S. (2005). Online news in Australia: Patterns of uses and gratifications. Australian Studies in Journalism, 15(6), 5-34.

Nuchso, N., Tuntivivat, S., \& Klayklueng, P. (2016). The effect of learning organization and servant leadership on childcentered teaching behavior with the mediating role of knowledge sharing in education of Chanthaburi diocese schools. International Journal of Humanities, Arts and Social Sciences, 2(5), 181-188. doi:https://doi.org/10.20474/jahss-4.2.3

Peng, H. P. (2019). An exploratory study of advancing interdisciplinary research trends in digital new media. Journal of Advanced Research in Social Sciences and Humanities, 4(5), 156-165. doi:https://doi.org/10.26500/jarssh-04-2019 $-0502$

Poindexter, P. M., \& McCombs, M. E. (2001). Revisiting the civic duty to keep informed in the new media environment. Journalism \& Mass Communication Quarterly, 78(1), 113-126. doi:https://doi.org/10.1177/107769900107800108

Schrøder, K. C. (2015). News media old and new: Fluctuating audiences, news repertoires and locations of consumption. Journalism Studies, 16(1), 60-78. doi:https://doi.org/10.1080/1461670x.2014.890332

Singer, J. B. (2001). The metro wide web: Changes in newspapers' gatekeeping role online. Journalism \& Mass Communication Quarterly, 78(1), 65-80. doi:https://doi.org/10.1177/107769900107800105

Sundar, S. S. (1998). Effect of source attribution on perception of online news stories. Journalism \& Mass Communication Quarterly, 75(1), 55-68. doi:https://doi.org/10.1177/107769909807500108

Sundar, S. S. (1999). Exploring receivers' criteria for perception of print and online news. Journalism \& Mass Communication Quarterly, 76(2), 373-386. doi:https://doi.org/10.1177/107769909907600213 
Sundar, S. S. (2000). Multimedia effects on processing and perception of online news: A study of picture, audio, and video downloads. Journalism \& Mass Communication Quarterly, 77(3), 480-499. doi:https://doi.org/10.1177/ 107769900007700302

Tewksbury, D., \& Althaus, S. L. (2000). Differences in knowledge acquisition among readers of the paper and online versions of a national newspaper. Journalism \& Mass Communication Quarterly, 77(3), 457-479. doi:https://doi.org/10.1177/ 107769900007700301

Tichenor, P. J., Donohue, G. A., \& Olien, C. N. (1970). Mass media flow and differential growth in knowledge. Public Opinion Quarterly, 34(2), 159-170. doi:https://doi.org/10.1086/267786

Uggur, N. G., \& Barutcu, M. T. (2018). Investigating social media activities: A study on celebrity posts. Journal of Advances in Humanities and Social Sciences, 4(2), 84-92. doi:https://doi.org/10.20474/jahss-4.2.3 